\title{
PELATIHAN PEREGANGAN DAN ISTIRAHAT AKTIF MENURUNKAN KELUHAN MUSKULOSKELETAL, KELELAHAN MATA DAN MENINGKATKAN KONSENTRASI KERJA KARYAWAN REKAM MEDIS RUMAH SAKIT SANGLAH DENPASAR
}

\author{
Eko Putu Indrawati, I Ketut Tirtayasa, I Putu Gede Adiatmika \\ Program Studi Magister Ergonomi-Fisiologi Kerja \\ Universitas Udayana Denpasar \\ Email:Indrawati1212@yahoo.co.id
}

\begin{abstract}
ABSTRAK
Bagian rekam medis (BRM) Rumah Sakit Sanglah saat ini telah menggunakan sistem komputerisasi, sehingga sebagian besar pekerjaan pengelolaan rekam medis pasien dilakukan dengan komputer. Berbagai keluhan fisik dijumpai pada pemakai komputer antara lain leher, bahu, lengan, pergelangan, tangan, dan kelelahan mata, yang dapat mengganggu kualitas dan produktivitas kerja karyawan. Perlu dilakukan intervensi terhadap karyawan BRM Rumah Sakit Sanglah. Tujuan pelatihan peregangan dan istirahat aktif untuk menurunkan keluhan tersebut serta meningkatkan konsentrasi kerjanya. Telah dilakukan penelitian dengan rancangan sama subjek pada karyawan BRM, sampel berjumlah 20 orang yang diberikan perlakuan daiam bentuk pelatihan peregangan dan istirahat aktif, Variabel yang diukur adalah keluhan musculoskeletal, kelelahan mata dan konsentrasi kerja. Hasil perlakuan antara sebelum bekerja dan sesudah bekerja pada Periode I dan Periode II dibandingkan dan dianalisis secara statistik.Hasil penelitian menunjukkan keluhan muskuloskeletal, kelelahan mata, dan konsentrasi kerja pada kedua perlakuan mengalami peningkatan setelah bekerja. Pada PI rerata skor keluhan muskuloskeletal 77,36 kelelahan mata 67,90, dan konsentrasi kerja dilihat dari kecepatan 26,03, ketelitian 18,01, dan konstansi 7,22. Sedangkan pada PII rerata skor keluhan muskuloskeletal 45,56, kelelahan mata 52,25, dan konsentrasi kerja dilihat dari kecepatan 15,00, ketelitian 13,50, dan konstansi 6,23. Pelatihan peregangan dan istirahat aktif ternyata menurunkan keluhan muskuloskeletal $71,98 \%$, kelelahan mata $46,73 \%$ dan meningkatkan konsentrasi kerja dilihat dari kecepatan 80,06\%, ketelitian $61,89 \%$, dan konstansi 40,08\%, sehingga ada pengaruh perbaikan terhadap kondisi kerja $(p<0,05)$. Disimpulkan bahwa pelatihan peregangan dan istirahat aktif menurunkan keluhan muskuloskeletal, kelelahan mata, dan meningkatkan konsentrasi kerja karyawan BRM Rumah Sakit Sanglah. Pelatihan peregangan dan istirahat aktif sebaiknya mulai digunakan dalam aktivitas kerja karyawan BRM Rumah Sakit Sanglah karena sudah terbukti mampu menurunkan keluhan muskuloskeletal, kelelahan mata, dan meningkatkan konsentrasi kerja karyawan.
\end{abstract}

Kata kunci: Pelatihan Peregangan, Istirahat Aktif, Keluhan Muskuloskeletal, Kelelahan Mata, Konsentrasi Kerja, dan Karyawan Bagian Rekam Medis 


\title{
ABSTRACT \\ STRETCHING TRAINING AND ACTIVE REST \\ DECREASE COMPLAINT OF MUSKULOSKLETAL, EYE FATIGUE, AND INCREASING THE WORK CONCENTRATION OF MEDICAL RECORD STAF OF SANGLAH HOSPITAL DENPASAR
}

\begin{abstract}
Currently, the department of medical recording of Sanglah hospital have utilized computerization system. So must of the medical the record of patiens was organized by the devices. Some of physical complaint always felt by operator computer, especially on their neck, shoulder, arm, wrist, hand and eyes that could be annoyed the quality and productivity of the employees. The stretching training and active rest should be done to the employees of the department of medical recording of Sanglah hospital decreasing all of the complaints and could be increasing their the work concentration. Has the studies to the sample subjek an employees BMR, sampel were 20 people give treatmentinmy form training stretching and active rest. Variabel measure is complait musculoskeletalm eye fatique and concentration work. Resul treatmen betwen before working and after work for the Periodic I and Periodic II compared and analyzed statistically.
\end{abstract}

In PI, the average score of musculoskeletal disorder is 77.36 , eye fatigue is 67.90 , and the work concentration which cover : speed 26.03, accuracy 18.01, and constancy 7,22. Mean while, in PII the average of score musculoskeletal disorder is 45.56 , eye fatigue is 52.25 , and the work concentration which cover : speed 15.00, accuracy 13.50, and constancy 6.23. According to that score could be knowing that the stretching training and active rest was decrease musculoskeletal disorder about $71.98 \%$, eye fatigue $46.73 \%$ and the work concentration which cover : speed $80.06 \%$, accurancy $61.89 \%$, and constancy $40.08 \%$. Which is in statistic this study was significantly $\mathrm{p}<0,05$

Therefore, could be concluded that stretching training and active rest decreasing musculoskeletal disorder and eye fatigue, and increasing the work concentration of BRM employees of Sanglah hospital. By doing so, that stretching training and active rest advisably to starts to be implemented in order to all of work activities of BMR employees of the hospital because the evident could be able to decrease musculoskeletal disorder, eye fatigue, and in order to increase employees" the work concentration.

Key words : Stretching Training, Active Rest Decreasing, Musculoskeletal Disorder, Eye Fatigue, the Work Concentration of Medical Recording Employees of Sanglah Hospital of Denpasar 


\section{PENDAHULUAN}

Setiap Rumah Sakit baik itu pemerintah maupun swasta memiliki dokumen yang harus tetap disimpan dan dijaga dengan baik, karena berkaitan langsung dengan jalannya instansi tersebut yang terkait dengan kinerja secara internal maupun secara eksternal. Dalam dunia kedokteran, arsip atau file sering disebut Rekam Medis. Rekam Medis adalah berkas yang berisi catatan dan dokumen mengenai identitas pasien, hasil pemeriksaan, pengobatan, tindakan dan pelayanan lainnya yang diterima pasien pada sarana kesehatan, baik rawat jalan maupun rawat inap (Permenkes, 2009). Rekam Medis sebagai milik pasien sekaligus sebagai milik rumah sakit atau institusi kesehatan merupakan data yang bersifat confidential menyebabkan BRM menjadi salah satu bagian yang penting di rumah sakit. Saat ini BRM Rumah Sakit Sanglah telah dilengkapi dengan sistem komputerisasi, sehingga mayoritas pekerjaan pengolahan rekam medis pasien menggunakan bantuan komputer.

Perkembangan sistem komputerisasi dalam kehidupan manusia, merupakan salah satu indikator perkembangan dunia teknologi yang tidak selamanya berdampak positif bagi kesehatan pemakainya. Berbagai gangguan kesehatan yang diakibatkan oleh pemakaian komputer antara lain repetitive strain injury (RSI), turunnya tingkat ketajaman mata dan sakit kepala, gangguan penglihatan, sakit punggung dan leher, gangguan mata itu sendiri, sakit pada tangan, pergelangan tangan, lengan, serta bahu. Selain itu, dampak negatif pemakaian komputer juga dapat menimbulkan ketegangan otot, kelelahan, rasa nyeri, computer vision syndrome, tendomiositis, carpal tunnel syndrome, dan masih banyak lagi (Kroemer and Grandjean, 2000). Hal tersebut disebabkan oleh sikap kerja pemakai komputer karena otot-ototnya bekerja secara cepat, statis dan berulang sehingga dapat menyebabkan timbulnya kelelahan (Widiastuti, 2005). Mayoritas karyawan pada BRM Rumah Sakit Sanglah bekerja menggunakan komputer, sehingga harus bekerja sambil duduk selama jam kerja. Jadwal kerjanya dimulai pukul 07.30 WITA sampai dengan pukul 14.00 WITA, maka jumlah waktu kerja sebanyak enam setengah jam. Selama 
bekerja enam setengah jam, karyawan duduk menghadap layar monitor komputer memakai stasiun kerja yang belum sesuai antropometri sehingga harus membungkuk selama bekerja.

Posisi duduk dalam waktu lama, dapat menimbulkan keluhan muskuloskeletal, kelelahan mata bahkan kurang konsentrasi kerja. Pelaksanaan aktivitas berhenti beberapa saat, hanya ketika harus mengambil rekam medis pasien atau istirahat untuk makan dan minum. Timbulnya berbagai keluhan tersebut dapat disebabkan oleh berbagai macam hal, antara lain postur kerja yang kurang fisiologis dan kurangnya pengetahuan tentang ergonomi. Postur kerja yang kurang fisiologis berupa posisi kaki menggantung karena tidak ada injakan kaki, punggung terlalu membungkuk, dan hiperekstensi leher yang sering dihubungkan dengan keluhan muskuloskeletal. Timbulnya berbagai sikap kerja yang kurang fisiologis dapat pula disebabkan, karena pemakai komputer kurang memahami tentang pengetahuan ergonomi. Pemberian instruksi peletakan meja, kursi dan monitor dengan benar dilaporkan sebesar
$61,2 \%$ dan instruksi waktu istirahat sebesar $71,5 \%$ pada pemakai komputer (Hakala dkk 2010).

Keluhan yang terjadi pada karyawan BRM, dapat diakibatkan oleh faktor internal dan eksternal tubuh. Pencegahan dapat dilakukan pada faktor internal yang meliputi: unsur somatik, di antaranya pengelolaan posisi tubuh agar biaya minimal. Sedangkan pencegahan pada faktor eksternal meliputi: pengaturan tugas, organisasi kerja dan lingkungan kerja tetapi menuntut biaya cukup besar (Adiputra, 1998). Berpegang pada kondisi riil Rumah Sakit Sanglah Denpasar, maka dilakukan perbaikan berkaitan dengan pencegahan keluhan faktor internal tubuh agar dapat mengurangi keluhan muskuloskeletal, kelelahan mata dan meningkatkan konsentrasi kerja karyawannya. Untuk mengatasi masalah tersebut di atas, maka dilakukan intervensi berupa kegiatan latihan peregangan dan istirahat aktif di sela-sela proses kerja pada karyawan di BRM Rumah Sakit Sanglah, sehingga otot menjadi relaks, mampu menurunkan keluhan muskuloskeletal, kelelahan mata dan agar konsentrasi kerja meningkat. 
Karyawan juga harus dapat segera mengalihkan perhatiannya pada aktivitas yang baru, bila aktivitas yang lain sudah berlalu sehingga mengurangi rasa bosan dalam bekerja bagi karyawan di BRM Rumah Sakit Sanglah.

Penelitian ini dimaksudkan untuk mengetahui manfaat dari latihan peregangan dan istirahat aktif terhadap penurunan keluhan muskuloskeletal, kelelahan mata dan peningkatan konsentrasi kerja karyawan BMR Rumah Sakit Sanglah. Perbaikan ini untuk memperoleh kondisi kerja yang efektif, nyaman, aman, sehat, efisien atau ENASE, produktif dan dapat meningkatkan kualitas hidup karyawan dengan biaya minimal.

\section{MATERI DAN METODE}

Penelitian ini adalah penelitian eksperimental dengan rancangan sama subjek atau treatment by subjects design (Bakta, 2000; Zainuddin, 1988; Pocock, 2008). Rancangan sama subjek adalah rancangan serial, karena semua sampel mengalami perlakuan yang sama dalam waktu berbeda. Rancangan ini diselingi washing out period yang diperlukan untuk menghilangkan efek perlakuan pada Periode I terhadap perlakuan pada Periode II. Pelaksanaan penelitian dibagi menjadi dua periode, Periode I bekerja tanpa mendapat perlakuan peregangan dan istrahat aktif. Pada Periode II bekerja dengan mendapat perlakuan peregangan dan istirahat aktif. Tiap periode dilakukan selama tiga hari, mulai pukul 08.00 12.00 Wita.

Jumlah sampel sebanyak 20 orang yang dipilih dengan menggunakan sampling acak sederhana (simple random sampling). Data sebelum dan setelah bekerja yang diukur adalah kondisi lingkungan, keluhan muskuloskeletal, kelelahan mata, dan konsentrasi kerja. Keluhan muskuloskeletal diukur dengan Kuesioner Nordic Body Map, kelelahan mata diukur dengan Kuesioner Kelelahan Mata Empat Skala Likert, dan konsentrasi kerja diukur dengan Bourdon Wiersma Test meliputi kecepatan, ketelitian, dan konstansi kerja. 


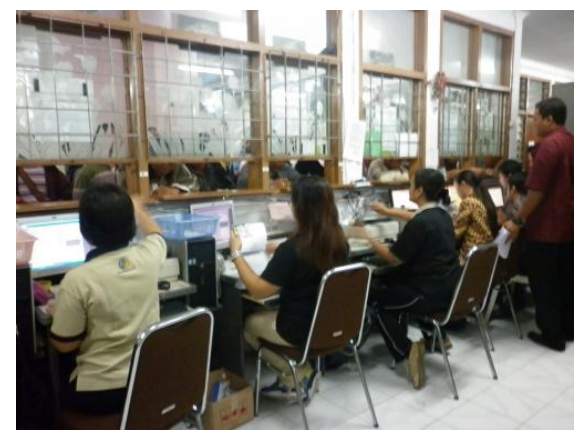

Gambar 1.1 Aktivitas Kerja Karyawan BRM RS Sanglah di sisi kanan dan kiri

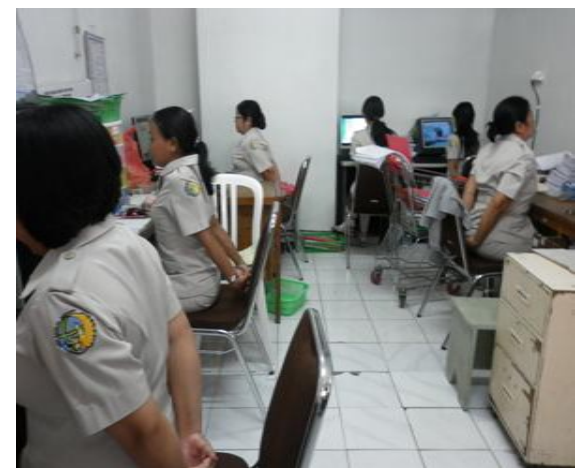

Gambar 1.2 Aktivitas Peregangan yang Diberikan di sisi kanan dan kiri

\section{HASIL DAN PEMBAHASAN}

\subsection{Karakteristik Subjek}

Pada penelitian ini, rerata umur adalah $39,75 \pm 8,37$ tahun masih tergolong usia yang produktif, karena subjek dapat melakukan aktivitas dengan kekuatan fisik yang optimal. Dikatakan oleh Kroemer and Grandjean (2000), bahwa puncak dari kekuatan otot untuk laki-laki maupun perempuan dicapai antara umur 25 s.d. 40 tahun. Berpedoman pada uraian tersebut, dapat disimpulkan bahwa semua umur subjek yang terlibat dalam penelitian ini termasuk dalam usia produktif yang dapat diartikan sedang berada pada kapasitas fisik yang optimal. Rerata berat badan dan tinggi badan jika dihitung dari rumus tinggi badan dikurangi $100 \pm$ hasil pengurangan dikalikan 10\% (Manuaba, $1998)$ berada dalam kondisi ideal $(56,65$ $\mathrm{kg})$. Perbandingan berat badan dan tinggi badan yang tidak ideal, dengan asumsi berat badan melebihi kemampuan daya 
penopang tubuh bisa menimbulkan nyeri pada lutut dan pergelangan kaki (Aryatmo, 1981). Subjek dalam penelitian ini memiliki rerata pengalaman kerja $17,80 \pm 8,94$ tahun yang berarti karyawan BRM Rumah Sakit Sanglah telah beradaptasi dengan kondisi kerja di lingkungannya. Pengalaman kerja karyawan tergolong sudah fasih mengerjakan semua tugas yang dibebankan kepadanya.

\subsection{Kondisi Lingkungan}

Kondisi lingkungan fisik yang diukur di lokasi penelitian meliputi suhu basah, suhu kering, kelembaban relatif ruangan, intensitas cahaya, dan kebisingan. Uji normalitas data kondisi lingkungan fisik dengan memakai uji Shapiro-Wilk karena jumlah sampel kecil $(\mathrm{n}<30)$.

Pada penelitian ini ditemukan rerata suhu basah Periode I adalah 25,08 $\mathrm{C}$ sedangkan pada Periode II adalah 26,05 C. Suhu kering yang ikut berkontribusi dalam menentukan mikroklimat di BRM Rumah Sakit Sanglah ternyata tidak melebihi batas kenyamanan yaitu rerata suhu kering pada Periode I adalah $24,85^{\circ}$ C sedangkan pada Periode II adalah $25,58^{\circ}$ C. Dalam hal ini Manuaba (1998) menyatakan, bahwa pada umumnya orang Indonesia masih dapat beraklimatisasi dengan baik pada kelembaban relatif 70 $80 \%$ dengan suhu $29-30^{\circ} \mathrm{C}$.

Dilihat dari rerata kelembaban relatif di BRM rumah sakit Sanglah, pada Periode I reratanya adalah 55,40\% sedangkan pada Periode II adalah $64,78 \%$. Hasil penelitian ini sesuai dengan Sumiratno (2010) yang menyatakan, kelembaban relatif di Bali berkisar antara 63-92\%. Menurut Kemenkes RI (2002), kelembaban relatif di lingkungan tempat kerja industri 6595\%. Menurut Manuaba (1998), agar tenaga kerja dapat bekerja selama 8 jam terus menerus tanpa adanya gangguan kesehatan dan nyaman maka diusahakan rata-rata kelembaban udara $60-70 \%$. Dengan demikian dapat dikatakan bahwa kelembaban relatif udara di tempat penelitian pada Periode I dan Periode II berada pada kategori nyaman. Dari hasil uji beda ditemukan, bahwa kelembaban relatif pada Periode I dan Periode II adalah tidak berbeda bermakna $(\mathrm{p}>$ 0,05). Hal ini menggambarkan, kelembaban relatif pada Periode I dan Periode II adalah sama. 
Pada penelitian ini ditemukan bahwa rerata intensitas cahaya pada Periode I adalah 114,75 lux sedangkan pada Periode II adalah 120,50 lux. Ini berarti, intensitas cahaya di tempat penelitian dalam kategori di bawah kenyamanan, sehingga berpengaruh terhadap kelelahan mata, mempengaruhi produktivitas kerja, menurunkan kualitas kerja, menimbulkan banyak kesalahan pada pegawai BRM. Berdasarkan uji beda ditemukan, bahwa intensitas cahaya pada Periode I dan Periode II adalah tidak berbeda bermakna (p > 0,05). Hal ini menggambarkan, intensitas cahaya pada Periode I dan Periode II adalah sama.

Pada penelitian ini ditemukan bahwa rerata tingkat kebisingan pada Periode I adalah 80,50 dB sedangkan pada Periode II adalah 80,75 dB. Menurut Suma'mur (1995), nilai ambang batas kebisingan yang dianjurkan untuk bekerja selama 8 jam sehari secara terus menerus adalah maksimal $85 \mathrm{~dB}$. Ini berarti, tingkat kebisingan di tempat penelitian dalam kategori nyaman.

\subsection{Keluhan Muskuloskeletal \\ Berdasarkan beberapa penelitian} yang dilakukan oleh pakar fisiologi kerja ditemukan bahwa sikap kerja yang kurang fisiologis (sikap statis dalam waktu relatif lama, gerakan memutar dan menunduk yang berulang) bisa mengakibatkan gangguan pada sistem otot rangka (Hales dkk., 1996; Yassierli dan Iftikar, 2000). Bhattacherjee dkk. (2003) melaporkan, bahwa gangguan muskuloskeletal menempati urutan pertama diantara penyakit akibat kerja lainnya yang dipengaruhi oleh karakteristik individu (umur lebih dari 30 tahun), karena pekerja yang mengalami gangguan tersebut berjumlah $44,9 \%$. 
Tabel 1

Hasil Uji t-paired Keluhan Muskuloskeletal

Karyawan BRM Sebelum dan Setelah Bekerja

\begin{tabular}{ccccccc}
\hline Variabel & & Periode & $\mathrm{n}$ & Rerata & $\mathrm{t}$ & $\mathrm{p}$ \\
\hline MSDs & Sebelum & Period I & 20 & 32,70 & 0,50 & 0,617 \\
& & Period II & 20 & 33,05 & & \\
& \multirow{2}{*}{ Setelah } & Period I & 20 & 77,36 & 8,70 & 0,000 \\
& & Period II & 20 & 45,56 & & \\
\hline
\end{tabular}

Berdasarkan Tabel 1. ditemukan bahwa hasil uji t-paired terhadap keluhan muskuloskeletal karyawan BRM sebelum bekerja baik pada Periode I dan II tidak berbeda bermakna $(\mathrm{p}>0,05)$. Hasil uji $t$ paired terhadap keluhan muskuloskeletal karyawan BRM setelah bekerja baik pada Periode I dan II menurun secara bermakna $(p<0,05)$.

Pada penelitian ini, Periode I didominasi oleh aktivitas dengan sikap kerja yang kurang fisiologis dan statis. Melalui pemberian latihan peregangan dan istirahat aktif pada Periode II, sikap kerja yang kurang fisiologis dan statis berhasil diubah menjadi sikap kerja yang fisiologis karena aktivitas karyawan

\subsection{Kelelahan Mata}

Hasil uji terhadap kelelahan mata dapat dilihat pada Tabel 2. tersebut telah didominasi oleh aktivitas yang dinamis. Hal ini ditentukan oleh adanya peningkatan skor keluhan muskuloskeletal setelah bekerja pada Periode I sebesar 44,66 dibandingkan setelah bekerja pada Periode II hanya meningkat 12,51. Jadi ada penurunan keluhan muskuloskeletal sebesar 71,99\% setelah dilakukan pelatihan peregangan dan istirahat aktif pada Periode II.

Hasil ini sejalan dengan penelitian Dewi (2012), bahwa pemberian peregangan otot peserta didik kelas $\mathrm{X}$ SMK Pariwisata Triatma Jaya di sela pembelajarannya dapat menurunkan keluhan muskuloskeletal secara bermakna yaitu sebesar $64,28 \%$. 
Tabel 2.

Hasil Uji t-paired Kelelahan Mata

Karyawan BRM Sebelum dan Setelah Bekerja

\begin{tabular}{|c|c|c|c|c|c|c|}
\hline Variabel & & Periode & $\mathrm{n}$ & Rerata & $\mathrm{t}$ & $\mathrm{p}$ \\
\hline \multirow{4}{*}{$\begin{array}{l}\text { Kelelahan } \\
\text { mata }\end{array}$} & \multirow[t]{2}{*}{ Sebelum } & Period I & 20 & 28,95 & 1,57 & 0,132 \\
\hline & & Period II & 20 & 31,50 & & \\
\hline & \multirow[t]{2}{*}{ Setelah } & Period I & 20 & 67,90 & 3,66 & 0,002 \\
\hline & & Period II & 20 & 52,25 & & \\
\hline
\end{tabular}

Tabel 2. menunjukkan hasil uji beda terhadap rerata skor kelelahan mata sebelum bekerja antara Periode I dan II adalah tidak berbeda bermakna ( $p>$ 0,05). Hal ini menandakan kelelahan mata subjek sebelum bekerja adalah sama. Hasil uji beda menunjukkan bahwa rerata skor kelelahan mata setelah bekerja antara Periode I dan II adalah berbeda bermakna $(\mathrm{p}<0,05)$.

Rerata skor kelelahan mata pada Periode I meningkat sebesar 38,95, sedangkan Periode II meningkat sebesar 20,75. Jadi ada penurunan kelelahan mata sebesar 46,73\%. Ini membuktikan bahwa aktivitas kerja karyawan BRM pada Periode II yang bekerja dengan tambahan sistem peregangan dan istirahat aktif lebih efektif karena peningkatan kelelahan mata yang ditimbulkan lebih kecil.

\subsection{Konsentrasi Kerja}

Pada penelitian ini konsentrasi kerja diukur memakai Bourdon Wiersma test. Oleh karena itu, tingkat konsentrasi kerja karyawan BRM RS Sanglah berhasil dimanifestasikan ke dalam kecepatan penyelesaian tes (detik), ketelitian (jumlah salah), dan konstansi dalam mengerjakan tes tersebut.

Beda rerata skor konsentrasi kerja yang dilihat dari kecepatan, ketelitian, dan konstansi menunjukkan bahwa beda rerata antara sebelum dan setelah bekerja menunjukkan kecepatan pada periode I adalah 13,74 dan periode II adalah 2,74, ketelitian pada periode I adalah 4,33 dan periode II adalah 1,65, konstansi pada 
periode I adalah 2,57 dan pada periode II adalah 1,54. Hasil tersebut menunjukkan adanya penurunan skor kecepatan, skor ketelitian dan skor konstansi. Ini berarti bahwa perbaikan yang dilakukan meningkatkan konsentrasi kerja karyawan BRM.

Tabel 3

Hasil Uji t-paired Konsentrasi Kerja Karyawan BRM

\begin{tabular}{|c|c|c|c|c|c|}
\hline Variabel & Periode & $\mathrm{n}$ & Rerata & $\begin{array}{l}\text { Beda } \\
\text { Rerata }\end{array}$ & $\mathrm{p}$ \\
\hline \multirow[t]{2}{*}{ 1. Kecepatan } & Period I & 20 & 26,03 & \multirow{2}{*}{11,03} & \multirow{2}{*}{0,000} \\
\hline & Period II & 20 & 15 & & \\
\hline \multirow[t]{2}{*}{ 2. Ketelitian } & Period I & 20 & 18,01 & \multirow{2}{*}{4,51} & \multirow{2}{*}{0,030} \\
\hline & Period II & 20 & 13,5 & & \\
\hline \multirow[t]{2}{*}{ 3. Konstansi } & Period I & 20 & 7,22 & \multirow{2}{*}{0,99} & \multirow[t]{2}{*}{0,000} \\
\hline & Period II & 20 & 6,23 & & \\
\hline
\end{tabular}

Tabel 3 menunjukkan uji t-paired terhadap konsentrasi kerja yang dilihat dari kecepatan, ketelitian, dan konstansi kerja karyawan BRM menunjukkan bahwa ada perbedaan penurunan skor kecepatan, skor ketelitian dan skor konstansi secara bermakna ( $p<0,05)$. Ini berarti perbaikan yang dilakukan pada karyawan BRM terbukti secara bermakna mampu meningkatkan konsentrasi kerja.
Peningkatan rerata skor kecepatan, ketelitian dan konstansi pada periode II lebih kecil dari pada periode I dan berdasarkan uji statistik berbeda secara bermakna $(p<0.05)$. Oleh karena itu dapat dibuktikan, bahwa aktivitas kerja karyawan BRM pada Periode II yang bekerja dengan tambahan sistem peregangan dan istirahat aktif lebih baik karena mampu meningkatkan konsentrasi 
kerja dimana kecepatan, ketelitian dan konstansi meningkat. Peningkatan kecepatan adalah 80,06 \%, ketelitian meningkat $61,89 \%$ dan konstansi meningkat $40,08 \%$.

Hasil penelitian ini bila dibandingkan dengan penelitian lain menunjukkan adanya kesamaan meskipun sampel penelitiannya adalah mahasiswa dan perawat. Penelitian Ariati (2008) dengan subjek penelitiannya mahasiswa Jurusan Gizi Poltekes Denpasar yang memberikan makronutrient pada makanan paginya diperoleh peningkatan kecepatan kerja skor $16,47 \%$ dan ketelitian kerja skor $18,32 \%$ serta konstansi kerja skor $12,57 \%$. Sedangkan pada penelitian Wijaya dkk (2006) yang sampel penelitiannya perawat yang bekerja pada instalasi rawat darurat di RS DR. Sardjito Yogyakarta mendapatkan rerata kecepatan kerja adalah skor 10,84 $\pm 3,68$ dan ketelitian kerja skor 5,68 2,90 serta konstansi kerjanya skor $8,70 \pm 2,90$.

\section{PENUTUP}

4.1 Simpulan

$\begin{array}{rr}\text { 1. Latihan peregangan dan } \\ \text { istirahat aktif menurunkan } \\ \text { keluhan } & \text { muskuloskeletal }\end{array}$

karyawan di BRM Rumah Sakit Sanglah Denpasar yaitu sebesar $71,98 \%$

2. Latihan peregangan dan istirahat aktif menurunkan kelelahan mata karyawan di BRM Rumah Sakit Sanglah Denpasar yaitu sebesar $46,73 \%$

3. Latihan peregangan dan istirahat aktif meningkatkan konsentrasi kerja karyawan di BRM Rumah Sakit Sanglah Denpasar dilihat dari kecepatan yaitu sebesar $80 \%$, ketelitian $\quad 61,89 \%, \quad$ dan konstansi $40,08 \%$

\subsection{Saran}

1. Karyawan BRM hendaknya memperhatikan waktu istirahat dan asupan gizinya ketika bekerja, sehingga keluhan yang ditimbulkan akibat aktivitas kerja dapat diminimalkan.

2. Sistem peregangan dan istirahat aktif sebaiknya mulai diterapkan pada aktivitas kerja karyawan BRM, karena sudah 
terbukti mampu mengurangi

keluhan muskuloskeletal dan

kelelahan mata yang diiringi

peningkatan konsentrasi kerja.

\section{RUJUKAN}

Adiputra, N.1998. Metodologi Ergonomi. Program Studi Ergonomi-Fisiologi Kerja. Program Pascasarjana Universitas Udayana Denpasar.

Ariati, I.N. 2008. Pengaruh Perbedaan Komposisi Makronutrient Makanan Pagi terhadap Prestasi Belajar Mahasiswa Jurusan Gizi Poltekes Denpasar. Tesis. Denpasar : Program Pasca Sarjana Universitas Udayana.

Aryatmo, T. 1981. Obesitas. Jakarta: Komisi Pengembangan Riset dan Perpustakaan. Fakultas Kedokteran Indonesia.

Bhattacherjee, A., Chau, N., Sierra, C.O., Legras, B., Benamghar, L., Michaely, J.P., Ghosh, A.P., Guilemin, F., Ravaud, J.F., Mur, J.M., Group, L. 2003. Relation of Job and Some Individual Characteritics to Occupational Injuries in Employed People: A Community-Based Study. J. Occup. Health, 45 (6,11): 382-391.

Dewi. 2011. Peregangan Otot di Sela Pembelajaran Mengurangi Kebosanan, Kelelahan dan Keluhan Muskuloskeletal pada Peserta Didik Kelas X SMK Pariwisata Triatma Jaya Badung. Tesis. Denpasar:
Program Pascasarjana Universitas Udayana.

Hakala, P. T., Saarni L. A., Ketola, R. L., 2010. Computer Associated Health Complaint and sources of ergonomic instructions in Computer Related Issues among Finnish Adolescents: A Cross Sectional Study. BMC Public Health. 10:11:1471-1478.

Hales, T.R., Bernard, B.P. 1996. Epidemiology of Work-Related Musculoskeletal Disorder. Orthop. Clin. North Am., Oct. 1996; 27(4): 679-709.

Kemenkes RI. 2002. Persyaratan Kesehatan Lingkungan Kerja Perkantoran dan Industri. Jakarta: Kemenkes RI.

Kroemer, K. H. E dan Grandjean, E. 2000. Fitting the Task to the Man, A Textbook of Occupational Ergonomics. $5^{\text {th }}$ Edition. London: Taylor \& Francis.

Manuaba, A. 1998. Dengan Desain yang Aman Mencegah kecelakaan dan Cedera. Bunga Rampai Ergonomi Vol 1. Denpasar: Program Studi Ergonomi-Fisiologi Kerja.

Permenkes. 2009. Definisi dan Isi Rekam Medis Sesuai Permenkes No: 269/Menkes/Per/Iii/2008.

Informasi rekam Medis. [cited 2011, Juli 12]. Available at: http/www.scribd.com/doc/3022719 4/apa definisi rekam-medis. 
Suma'mur, P. K. 1995. Higene Perusahaaan dan Kesehatan Kerja. Jakarta: PT, Penerbit PT Gunung Agung.

Sumiratno. 2010. Laporan Suhu Udara di Wilayah III. Denpasar: Balai Besar Meteorologi dan Geofisika Wilayah III Denpasar.

Widiastuti, M. I. 2005. Aspek Anatomi Terapan pada Pemahaman Neuromuskuloskeletal Kepala dan Leher sebagai Landasan Penanganan Nyeri Kepala. Semarang: Tegang Prima.
Wijaya, Lientje Setyawati, Endang Suparniati. 2006. Hubungan antara Shift Kerja dengan Gangguan Tidur, Konsentrasi Kerja dan Kelelahan Kerja Perawat Instalasi Rawat Darurat Rumah Sakit Dr. Sardjito Yogyakarta. (Makalah). Yogyakarta: Sekolah Pascasarjana Universitas Udayana.

Yassierli dan Iftikar. Z, S. 2000. Evaluasi dan Analisis Postur Kerja dalam sistem Kerja Permesinan Konvensional Indonesia. Dalam; Wignyosoebroto, S \& Wiratno, S.E. Editors. Prosiding Seminar Nasional Ergonomi 2000. Surabaya: Guna Wijaya. 